\title{
Employee well-being in the COVID-19 pandemic: The moderating role of teleworking during the first lockdown in the province of Quebec, Canada
}

\author{
Annick Parent-Lamarche ${ }^{\mathrm{a}, *}$ and Maude Boulet ${ }^{\mathrm{b}}$ \\ a Department of Human Resources Management, Université du Québec à Trois-Rivières, Trois-Rivières, Quebec, \\ Canada \\ ${ }^{\mathrm{b}}$ École Nationale d'Administration Publique, Quebec, Quebec, Canada
}

Received 10 December 2020

Accepted 7 July 2021

\begin{abstract}
.
BACKGROUND: The COVID-19 pandemic has had a profound effect on all aspects of society, including mental health. Many employees have had to pivot suddenly to teleworking to prevent the virus from spreading. While teleworking may have some negative consequences, it may also represent a human resources practice that may improve employee well-being.

OBJECTIVE: The study main objective was to determine if teleworking played a moderating role in the relation between potential stressors and employee well-being during the first months of the COVID-19 pandemic when working from home. This was based on the theory of conservation of resources.

METHODS: Multivariate regression analyses were conducted with Stata 13 software to determine the contribution of potential stressors on employee well-being, as well as the moderating role of teleworking on a sample of 480 Canadian employees. Data were collected once for white and blue collar from both public $(67.08 \%)$ and private $(32.92 \%)$ business sectors.

RESULTS: Results indicated that work-life imbalances, workload, and marital tension were associated with lower levels of well-being. On the other hand, teleworking and household income were associated with higher levels of well-being. Teleworking also moderated the differences in well-being between the public and private sectors. Teleworking in the public sector seems to increase employee well-being. Conversely, working on-site in the public sector seems to decrease well-being. CONCLUSIONS: Employers need to proactively address work-life imbalances, workloads, and teleworking to maintain employee well-being. Specific recommendations are offered to ensure that teleworking remains positive for employee wellbeing both during a pandemic and afterward.
\end{abstract}

Keywords: COVID-19, teleworkers, well-being, conservation of resources theory, business sector

*Address for correspondence: Annick Parent-Lamarche, Department of Human Resources Management, Université du Québec à Trois-Rivières, 3225, Albert-Tessier, Trois-Rivières, Québec G9A 5A7, Canada. E-mail: Annick.Parent-Lamarche@uqtr.ca.

\section{Introduction}

The coronavirus disease 2019 (COVID-19) pandemic has had a profound effect on all aspects of society, including mental health [1]. The pandemic is 
a threat not only to the public's physical health but to its mental health as well [2]. Many of the major stressors, including lockdown directives, disrupted travel plans, social isolation, feelings of insecurity, media information overload, and panic buying of household necessities, have led to anxiety and depression [3]. In addition, many employees have been suddenly forced into teleworking to prevent the virus from spreading. Teleworking can be defined as working outside the conventional workplace and communicating with it by way of telecommunications or computer-based technology [4]. Kurland and Bailey identified four types of telework: home-based telecommuting, satellite offices, neighborhood work centers, and mobile working [5]. Robertson et al. referred to a virtual work location (e.g., home) [6]. According to Tremblay et al., studies distinguish between various forms of telework (e.g., work done in clients' offices, work in business centers or satellite offices) of which working from home with ICTs is one form [7]. In the case of the present study, telework correspond to a situation where an employee had to work from home due to the COVID-19 pandemic. According to Galea et al., shutdowns of usual day-to-day life operations will undoubtedly have consequences on people's mental health and well-being, even in the short term [8]. Mental health should not be considered less important than physical health [9]. However, the existing literature on the mental health consequences of epidemics looks at the sequelae of the diseases themselves rather than the stressors related to them [8]. Furthermore, few studies have specifically examined the effect of the pandemic on employee well-being, but it is important to do so, since well-being is an important foundation for employee motivation, effort, work behaviors, interpersonal relationships, commitment, and performance $[10,11]$. These outcomes are still of great importance, even during a pandemic.

Moreover, low levels of well-being have been negatively associated with employee performance at work [12]. High levels of employee well-being benefit both employees themselves and their employers, as they maximize the chance of success, according to Giorgi et al. [13]. As mentioned above, employee well-being is still of great importance during a crisis. The current COVID-19 pandemic provides an opportunity to explore the effects of the crisis and of a flexible work arrangement — that is, teleworking —on employee well-being [14]. It may also teach employers how to improve employee well-being [14].

This cross-sectional study aimed to evaluate the effect of potential stressors and if teleworking played a moderating role, as an organizational resource/human resources practice, on well-being in a sample of 480 Canadian employees. This study contributes to the existing literature by analyzing the effects of potential stressors and the possible moderating effect of teleworking on well-being in the extraordinary conditions of a government-imposed shutdown. We were not able to find any studies on how teleworking played a moderating role in the relationship between stressors and employee well-being during the first months of the COVID-19 pandemic in the province of Quebec, Canada.

\section{Empirical background}

\subsection{Well-being}

Well-being pertains to optimal experience and functioning. There are two main types of well-being, hedonic and eudaimonic [15]. Hedonic well-being refers to whether a person feels happy or experiences pleasure and lacks pain [15], whereas eudaimonic well-being refers to whether they have attained self-realization, a sense of purpose, and are fully functioning [15]. According to Schütte et al., well-being is a part of optimal mental health [16]. Well-being includes both positive (e.g., job satisfaction and engagement) and negative components (e.g., psychological distress, depression) [17]. Previous studies have also distinguished between an overall state of well-being, such as life satisfaction [18], and one that is contextualized within one's work, such as job satisfaction [19]. That said, well-being is not merely the absence of mental illness [20]. For instance, the absence of depressive symptoms does not necessarily mean that the person is in a state of well-being.

The scarcity of studies of well-being at work is also a concern. Work-related well-being (e.g., job satisfaction) has been studied in the scientific literature $[21,22]$, but the broader construct of the well-being of global employees has lagged behind [23]. In this paper, we will use a comprehensive, subjective measure of well-being, the World Health Organization's Well-being Index (WHO-5) [24], a measure of well-being that is not strictly related to work or life satisfaction. Although life satisfaction can be used as a proxy for happiness [25], we chose to use a positive mental health indicator. The WHO5 , a measure of psychological well-being, comprises several elements related to well-being that go above and beyond the absence of depressive symptoms [26]. 
The positive elements of well-being are thus more likely to represent a positive state of mind that might be beneficial in the current crisis. It should also be noted that the WHO-5 has been previously used to assess employees' mental health and well-being at work [27, 28]. We therefore chose to use the WHO's definition of well-being, which comprises good mood, vitality, and interests a person might still have despite the pandemic.

Employee well-being can be examined through the lens of the theory of conservation of resources (COR) [29]. This theory states that individuals actively attempt to retain, protect, and build resources and that they experience stress and low well-being over the loss of these potential or actual valued resources [29]. Resources can be internal or external to the individual and relate to all areas of an individual's life. For instance, when people face stressors (e.g., worklife imbalances) that exceed their resources, or when resources are not replenished, people experience stress and low well-being. Personal characteristics (e.g., educational level), object resources (e.g., household income), and life conditions (e.g., marital status) are all examples of resources [29]. Therefore, we were interested in identifying potential stressors (loss of resources) related to well-being during a pandemic.

\subsection{Potential stressors related to well-being}

There are several potential stressors and risk factors that may be associated with an individual's psychological health or well-being. We have included some of these risk factors to assess their effects on employee well-being both in normal times and during a pandemic in line with COR theory. They will be discussed in the sections below.

\subsubsection{Work-life imbalance}

The ability to balance one's work and (family and/or personal) life is a strong contributor to how well an individual feels [30]. Empirical studies show that work-life imbalance is associated with a lower level of well-being [30, 31]. In the 2010 European Working Conditions Survey of 24,096 employees in 27 European countries, respondents reporting worklife imbalances also reported more health problems (e.g., poor well-being; $\mathrm{OR}=2.06,95 \%$ CI [1.83, 2.31]) [32]. This leads us to believe that this could be a stressor for employees during a pandemic, because many parents have had to work from home with their children around.

\subsubsection{Business sector}

Public sector employees have generally been perceived as being more dissatisfied with their jobs compared to their private sector counterparts [33, 34]. One possible cause of this dissatisfaction is that although public organizations have missions that often provide greater opportunities for employees to achieve altruistic or higher-order needs, the very structure of those organizations-characterized by greater red tape and conflict-prevents those opportunities from being realized [35].

During the pandemic, public employees have faced major challenges. For example, teachers have had to pivot to remote teaching with no preparation. Then there are healthcare employees providing essential services. The pandemic may be positive for them if they see it as a challenge or negative if they perceive it as a stressor. According to Imamoğlu and Beydoğan, business sector was a predictor of employee wellbeing only indirectly, as a measurement of employee perception of support and whether their needs were being met at work [36]. To our knowledge, no empirical studies have demonstrated a specific, direct effect of working in the public sector versus the private sector on employee well-being during a pandemic. We therefore took it upon ourselves to examine the differences between employee well-being in the public and private sectors.

\subsubsection{Workload}

According to Shaw and Weekley, workload usually refers to an employee's quantity of tasks and the difficulty of a task. [37]. It might exert a psychological strain on employees, such as work rhythm and opposing demands [38]. As for its association with psychological health, previous studies have identified a negative link between workload and well-being [16, 39-42]. More specifically, an employee facing a high workload is likely to experience a poor level of well-being. Nevertheless, no study has investigated this association during a pandemic.

\subsubsection{Marital status}

Being in a relationship was associated with lower psychological distress [43, 44], lower burnout [45], and higher well-being [46]. Therefore, it was expected that marital status (being in a relationship) would have a positive effect on well-being during a pandemic. 


\subsubsection{Marital tension}

Strained relations with a spouse or life partner have been associated with higher psychological distress $[43,44]$. Marital stability, on the other hand, was associated with higher well-being in a recent study [47]. In a pandemic, and even more so during lockdown, marital tension would be expected to be associated with lower well-being, since spouses are forced to spend more time together than usual.

\subsubsection{Parental status}

While some studies have found that being a parent had no significant effect on psychological health $[44,48]$, others have found a positive impact. More precisely, it has been associated with lower levels of burnout [49] and higher levels of well-being [46]. As a result, parental status might affect employee well-being during a pandemic.

\subsubsection{Household income}

A household's financial situation has been associated with psychological health in some empirical studies. For instance, household income has been associated with lower psychological distress [44], lower burnout [45], and higher psychological wellbeing [50, 51]. Because the pandemic is causing a great deal of uncertainty and feelings of insecurity, a strong financial situation is likely to protect an individual's well-being, and the reverse is also likely true.

\subsubsection{Gender}

Prior to the pandemic, studies showed that being female was associated with higher rates of mental health issues [52, 53]. During the pandemic, women's well-being is more likely to be affected than men's [54]. In fact, being female was found to be a risk factor for stress and distress during the pandemic $[55,56]$. [57] also found that women were at higher risk for anxiety.

\subsubsection{Job insecurity}

Job insecurity is one of the most common stressors in twenty-first-century working life [58]. Sverke et al. define job insecurity as the subjective experience of anticipating a fundamental, involuntary event related to job loss [59]. Job insecurity also refers to a perceived negative change to one's job and the emotional reactions to a potential change to one's job components [58]. A recent review showed that a lack of job security harms mental health [60]. More recently, a feeling of job insecurity was found, unsurprisingly, to be negatively associated with employee well-being
[42]. This association has yet to be demonstrated in a pandemic.

\subsection{Role of teleworking}

In 2013, Yahoo CEO Marissa Mayer banned Yahoo employees from working from home [61] in an attempt to foster a more inventive, collaborative environment. But Goudreau called the move a return to the Stone Age, implying that Mayer is out of touch with the times [62]. In fact, most employees would like more flexibility at work to help them reconcile their personal and professional lives [62]. COVID19 could be the impetus needed to make teleworking more commonplace [63]. Many employees in many countries have been required to stay at home and away from their workplace to control the spread of COVID-19, making teleworking practices much more widespread [64].

Before the pandemic, teleworking or working from home presented several advantages and challenges for individuals and organizations according to Kurland and Bailey [5]. A greater productivity, lower absenteeism, lower turnover are examples of organizational advantages [5], while reduced mentoring, informal interaction and work coordination are examples of organizational challenges [5]. At the individual level, less time commuting, work-family balance, costs savings, reduced stress, more autonomy and comfortable work environment were given as example of advantages, while social and professional isolation and reduced access of resources were presented as example of challenges by Kurland and Bailey [5]. In a similar vein, Greer and Payne mentioned that teleworking seems to facilitate flexibility and work-life balance [65]. Teleworking can also cause employees to work more hours as the boundaries between their personal and professional lives are blurred $[66,67]$. A recent literature review concluded that, overall, teleworking during normal times is likely to yield more good than bad consequences for individual health [67]. For example, telework has been associated with lower levels of work exhaustion [68]. Additionally, another recent systematic review prior to the pandemic concluded that remote e-working was found to associate with individuals' positive emotions and to ameliorate feelings of emotional exhaustion [69].

However, it might not be the same in a pandemic. Teleworking makes it possible for a company to continue operating while protecting employee health and safety during a pandemic and allows employees to 
continue earning an income while staying home [70]. The current situation is an unprecedented one in which most organizations have asked employees to work remotely due to exceptional circumstances [71]. As stated by Hobfoll, external events often threaten an individual's resources [29]. The COVID-19 crisis is a perfect example, as normal life has been disrupted. This is especially true for employees, since they face additional potential resource losses, such as sudden job insecurity and less face-to-face social support from supervisors and coworkers. One of the main corollaries of the COR theory says that individuals with greater resources are less vulnerable to resource loss and more capable of resource gain [72], and conversely, individuals who lack resources are more vulnerable to resource loss and less capable of resource gain [72]. The theory also says that the adjustment of resources to external demands leads to stress and low well-being [72]. Nevertheless, only a few empirical studies examined how teleworking affects employee well-being specifically during a pandemic [73]. One quantitative empirical study by Ipsen et al. found that most people had more positive rather than negative experience of working from home in early lockdown [74]. Kirchner et al. found that working from home has benefits for the employees, such as more flexibility in the working day and less commuting time [75]. Moreover, it was established that the experience of working from home during the COVID crisis appears to have been a positive one for the majority of employees [76]. For their parts, Bolisani et al. found that employees who worked from home during the COVID-19 pandemic mostly appreciated the time saved for transportation time, the possibility to eat and drink their own food, to better focus on work without interruptions, and to be close to family [77]. Although they found some obstacles as well (e.g., difficulty to see colleagues or other people), they were, on the whole, perceived as less significant than benefits [77].

However, we were not able to locate any study that specifically tap into the possible moderating role of teleworking, as an organizational resource/human resources practice, on the relationship between potential stressors and well-being during a pandemic.

\section{Theoretical model}

Building on the COR theory, the IGLO (individual, group, leader, organizational) model offers a pragmatic classification of resources according to their provenance [78]. It is possible to quantify and qualify employees' resources on an individual level (e.g., educational level), as well as the resources from their group (e.g., social support from colleagues), leader (e.g., quality of support from the manager or immediate superior), and organization (e.g., teleworking policy). In this study, we focus on individual (e.g., marital status) and organization levels resources (e.g., teleworking). As specified in the COR theory, having an abundance of resources creates a "reservoir" for future stressful situations and is a predictor of employee well-being [29].

Delving deeper, Guest suggests focusing on things companies can do to help improve their employees' well-being [79]. These include human resources practices, such as family-friendly work arrangements and building autonomy and flexibility into job descriptions [79]. Teleworking is thus a human resources matter that has the potential to affect employee well-being. According to a recent literature review, teleworking can either mitigate or aggravate the effects of COVID-19 (i.e. play a moderating role) on employees' mental health [64].

Considering the above, we postulate that teleworking during a pandemic, as an organizational resource/human resources practice, may moderate the impact of potential stressors, since teleworking lowers the risk of contracting the virus, and the perception of safety, threat, and risk of contagion is considered a major stressor during a pandemic [80, 81]. Teleworkers also spend less time commuting compared to on-site workers, saving them time and offering them flexibility [65].

Hypothesis. Teleworking moderates the effects of potential stressors on Canadian employee well-being during the first months of the COVID-19 pandemic.

\section{Method}

\subsection{Participants}

This study was based on a sample of 480 employees (67.08\% from public sector and $32.92 \%$ from private sector) in the province of Quebec in Canada. They were recruited via social media posts on Facebook, Instagram, and LinkedIn between April 28 and June 28, 2020. The link to the questionnaire was also shared on the websites of Mouvement Santé Mentale Québec (a grouping devoted to create, develop and strengthen mental health), the Ordre des conseillers en ressources humaines agrees (Certified Human 
Resources Professional), and the École de Relations Industrielles, Université de Montréal (School of Industrial Relations, University of Montreal) during that period. A study of this online sampling strategy concluded that the strategy was valid and led to results indistinguishable from that of a standard sample [82].

Participants completed the online questionnaire (See "Measurements" section for details) individually on their own time. They read instructions on confidentiality and then signed an informed consent form. No financial compensation was given. The sample was $81.7 \%$ female, ranging in age from 20 to 70 (mean age $=41.1 ; \mathrm{SD}=5.3$ years). The research protocol was approved by the ethics committees of the University of Public Administration and the University of Quebec in Trois-Rivières.

\subsection{Measurements}

\subsubsection{Well-being}

Well-being was measured using the five-item WHO Well-Being Index (WHO-5) [83]. The WHO5 comprises five items on a six-point Likert scale (where $0=$ At no time and $5=$ All of the time). One example of an item is "I have felt calm and relaxed." Internal consistency was adequate $(\alpha=0.97)$. Wellbeing was treated as a continuous variable in the statistical analysis.

\subsubsection{Potential stressors related to well-being}

Work-life imbalance. This was measured with a single item ("Since the start of the COVID-19 crisis, how satisfied have you been with the balance between your job and your home life?") on a five-point Likert scale ( $1=$ Very satisfied, $5=$ Very dissatisfied). Work-life imbalance was treated as dichotomous in the analysis $(0=$ Satisfied, Very satisfied or Neither satisfied or dissatisfied and 1 = Dissatisfied or Very dissatisfied).

Business sector. This was measured with a single item ("Is your job in the public sector?") and was coded as $0=$ No and $1=$ Yes.

Workload. This was measured with a single item ("Since the start of the COVID-19 crisis, what situation best matches your workload?") on a five-point Likert scale $(0=$ Decrease, Large decrease, or Same as before and $1=$ Increase or Large increase). Workload was treated as dichotomous in the analysis ( $0=$ Decrease or Same as before and $1=$ Increase $)$.

Marital status. This was coded as $0=$ Single and $1=$ Living as a couple.
Marital tension. This was measured with a single item ("How has the COVID-19 crisis affected the tensions in your relationship?") and was coded as $0=$ "The COVID-19 crisis has decreased or has not changed the tensions in my relationship" and $1=$ "The COVID-19 crisis has increased the tensions in my relationship."

Parental status. This was coded as $0=\mathrm{No}$ and $1=$ Yes for having children under the age of 18 .

Household income. This was coded using pretax household income for the preceding 12 months on a 12-point scale $(1=$ Less than $\$ 20,000$ and $12=\$ 120,000$ or more).

Gender. This was coded as $0=$ Male and $1=$ Female.

Job insecurity. This was measured with a single item ("Could you lose your job in the next month due to the current COVID-19 crisis?") on a fivepoint Likert scale $(1=$ Strongly agree, $5=$ Strongly disagree). Job insecurity was treated as dichotomous in the analyses $(0=$ Strongly disagree, Disagree or Neither agree nor disagree and $1=$ Strongly agree or Agree).

\subsubsection{Teleworking}

Teleworking was measured with a single item ("Which statement best describes how you perform your work during the COVID-19 crisis?") and was coded as $0=$ "I go to my usual place of work" and $1=$ "I work from home."

\subsubsection{Control variables}

Age was coded in number of years. Employment stability was measured with a single item ("What is the employment situation that best matches your employment situation since the start of the COVID19 crisis?") and was coded as $0=$ "My working hours or employment income has been reduced" or "I lost my job or my business has made me temporarily unemployed due to COVID-19" and 1= "I still have my job(s), with no loss of working hours or employment income." Educational level was coded using the highest degree attained by the respondent on a 10-point scale ranked based on the number of years necessary to obtain the degree (lowest to highest $)(1=$ None, $2=$ High school, $3=$ Professional school, $4=$ College (General), 5=College (Technical), $6=$ University (Undergraduate certificate), $7=$ University (Bachelor's), $8=$ University (Graduate degree), $9=$ University (Master's), $10=$ University (Doctorate). Impact of the COVID-19 crisis on worklife balance satisfaction was measured with a single 
Table 1

Descriptive correlational statistics

\begin{tabular}{|c|c|c|c|c|c|c|c|c|c|c|c|c|c|}
\hline & $\mathrm{M}$ & $\mathrm{SD}$ & 1. & 2. & 3. & 4. & 5. & 6. & 7. & 8. & 9. & 10. & 11. \\
\hline 1. & 12.29 & 5.28 & 1 & & & & & & & & & & \\
\hline 2. & 83.96 & & $0.01^{*}$ & 1 & & & & & & & & & \\
\hline 3. & 47.08 & & $-0.19^{* *}$ & -0.05 & 1 & & & & & & & & \\
\hline 4. & 67.08 & & -0.01 & -0.05 & 0.01 & 1 & & & & & & & \\
\hline 5. & 46.25 & & $-0.15^{* *}$ & -0.04 & $0.15^{* *}$ & -0.05 & 1 & & & & & & \\
\hline 6. & 77.50 & & 0.07 & 0.06 & -0.01 & -0.01 & 0.04 & 1 & & & & & \\
\hline 7. & 39.58 & & $-0.22^{* *}$ & -0.03 & $0.15^{* *}$ & -0.02 & -0.03 & $0.26^{* *}$ & 1 & & & & \\
\hline 8. & 64.38 & & 0.01 & -0.01 & 0.08 & $0.09^{*}$ & 0.04 & $0.29^{* *}$ & $0.16^{* *}$ & 1 & & & \\
\hline 9. & 6.30 & 1.87 & $0.12^{*}$ & $0.10^{*}$ & 0.02 & 0.05 & 0.06 & $0.52^{* *}$ & $0.16^{* *}$ & $0.31^{* *}$ & 1 & & \\
\hline 10. & 81.67 & & -0.06 & -0.02 & -0.06 & -0.05 & 0.05 & -0.04 & 0.04 & -0.02 & -0.05 & 1 & \\
\hline 11. & 8.96 & & -0.01 & 0.02 & -0.02 & $-0.18^{* *}$ & -0.04 & $-0.11^{*}$ & -0.05 & $-0.10^{*}$ & $-0.10^{*}$ & 0.04 & 1 \\
\hline
\end{tabular}

Note $\mathrm{a}:{ }^{*} p \leq 0.05$ (coefficients $\geq 0.05$ ) and ${ }^{* *} p \leq 0.01$ (coefficients $\geq 0.05$ ). Note $\mathrm{b}: \mathrm{M}=\mathrm{Mean} /$ Proportion; $\mathrm{SD}=\mathrm{Standard} \mathrm{deviation;} 1 .=\mathrm{Well}-$ being; 2. = Teleworking; 3. = Work-life imbalance; 4. =Sector (public); 5.=Workload (elevated); 6. = Marital status (living as a couple); 7. = Marital tension; 8. = Parental status (children); 9. = Household income (12 categories); 10. = Gender (female); 11. = Job insecurity.

item ("How has the COVID-19 crisis affected your level of satisfaction with the balance between your job and your home life?") and was coded as $0=$ "The COVID-19 crisis has increased or has not changed my level of satisfaction" and 1= "The COVID-19 crisis has decreased my level of satisfaction."

Personal characteristics, such as age and educational level, were previously found to be associated with psychological health [45]. Our statistical analysis was therefore adjusted for covariates to capture the effect of the variables central to this study.

\subsection{Data analysis}

Multivariate regression analyses [84] were conducted with Stata 13 software. To determine the contribution of potential stressors, teleworking, and control variables on employee well-being, we included them in a multiple regression model. We then introduced the interaction variables $(n=9)$, which are teleworking combined with every potential stressor according to Dawson's recommendations [85]. The significance threshold used for the interactions was $p \leq 0.005$ after the Bonferroni correction. To reject the null hypothesis, we used a two-tailed test with $p \leq 0.05$. This allowed us to determine the significance level of the combined variables, as well as that of each individual regression coefficient. The coefficients were examined based on halved $p$-values [84].

\section{Results}

Table 1 presents the descriptive statistics for the sample variables of interest, along with the correlational analyses. The results show that the well-being
Table 2

Direct effect of potential stressors on employee well-being

\begin{tabular}{lcc}
\hline & Model 1 & Model 2 \\
\hline Fixed part & & \\
$\quad$ Constant & $12.29^{* *}$ & $12.47^{* *}$ \\
Potential stressors & & \\
Teleworking & & $1.30^{*}$ \\
Work-life imbalance & $-3.72^{* *}$ \\
Sector (public) & -0.19 \\
Workload & $-1.24^{* *}$ \\
Marital status (living as a couple) & 0.42 \\
Marital tension & $-1.44^{* *}$ \\
Parental status (children) & 0.80 \\
Household income & $0.32^{*}$ \\
Gender (female) & 0.02 \\
Job insecurity & -0.60 \\
Fit & \\
F-test & 19.27 \\
$D f$ & $(14)^{* *}$ \\
Adjusted R-squared & 0.348 \\
\hline
\end{tabular}

Note. ${ }^{*} p \leq 0.05$ and ${ }^{* *} p \leq 0.01$. The following variables were controlled for: age, educational level, employment stability, impact of the COVID-19 crisis on work-life balance satisfaction (unstandardized coefficients).

score is relatively low (49.16\%), although a specific cut-off value has not been established. By the scoring principle, the raw score, which ranges from 0 to 25 , is multiplied by 4 to obtain the final score, which ranges from 0 (the worst imaginable well-being) to 100 (the best imaginable well-being) [24].

Table 2 presents the main effect of potential stressors (Work-life imbalance, Business sector, Workload, Marital status, Marital tension, Parental status, Household income, Gender, and Job insecurity) and of Teleworking on Well-being. Work-life imbalance, workload, and marital tension were negatively associated with well-being. Conversely, teleworking and household income were positively 


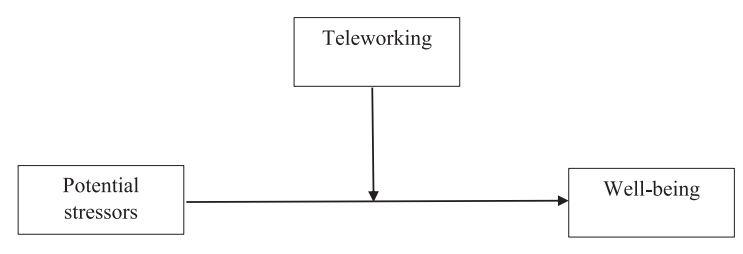

Notes. See Table 2 for the direct effects of potential stressors on well-being. See

Figure 2 for the moderating effect of

teleworking on the relationship between

potential stressors and well-being.

Fig. 1. Hypothetical model.

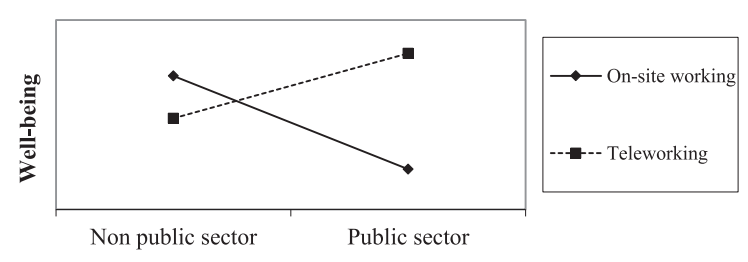

Fig. 2. Interaction of teleworking and business sector on employee well-being.

associated with employee well-being. Finally, the fit indices showed that the model met the recommended criteria [84].

\subsection{Interaction results}

After applying the Bonferroni correction ( $p \leq$ 0.005 ) to all nine interaction tests, only the business sector interacted with teleworking (F-test $=19.68$; $D f=15 ; p \leq 0.05)$ to explain employees' levels of well-being. As shown in Fig. 1, teleworking $(\beta=4.79 ; p \leq 0.005)$ payed a moderating role in the relationship between business sector and wellbeing. Public sector employees experienced greater well-being when teleworking, and conversely, their well-being diminished when working on-site. In the private sector, teleworking did not make a significant difference in well-being. Rather than supporting a general direct effect from public sector work on wellbeing, the results indicated that teleworking alters the conditions in which public sector work is associated with well-being.

\section{Discussion}

The main objective of this study was to determine if teleworking played a moderating role between potential stressors and well-being during the first months of the COVID-19 pandemic in the province of Quebec, Canada. The results partially supported our hypothesis and indicated that work-life imbalance, workload, and marital tension were associated with lower levels of well-being. Conversely, teleworking and household income were associated with higher levels of well-being. These results are consistent with the literature prior to the pandemic on work-life imbalance [31, 32], workload [16, 39-42], and marital tension [47]. Overall, the results indicated that these three potential stressors were detrimental to employee well-being during a pandemic as well, which is not surprising and is in line with the COR theory, the theoretical model proposed in this paper. The COR theory states that individuals who lack resources are more vulnerable to resource loss, which can lead to lower levels of well-being.

The results were consistent with empirical studies on teleworking $[68,73]$ and household income $[50,51]$. Teleworking and having a higher household income seemed to favor employee well-being during a pandemic. Our results agreed with the COR theory, which postulates that individuals with greater resources are less vulnerable to resource loss, leading to greater well-being. As stated previously, some studies have shown that teleworking may also have negative consequences on well-being, since it exacerbates isolation [67].

One explanation for our result might be that the use of digital technologies helps bridge social distances during lockdown [86]. Furthermore, according to Mayo et al., "white-collar" employees and knowledge-oriented industries are more likely to use teleworking practices [87]. This may also partly explain the results of this study. Indeed, the respondents' high education levels are likely to have contributed to the fact that telework was associated with wellbeing. Such employees may have adapted to imposed telework more easily, since they have probably done it in the past to some extent as they possibly had jobs that could be conducted from home before. The increasing intensity of modern work life also requires extensive time and energy from employees [88], possibly explaining why teleworking was associated with greater well-being for public sector employees. It is possible that employees not directly exposed to the virus felt relief since they were at less risk, offsetting the stress of the pandemic. This is especially true for public sector employees (e.g., education, health), since they would have had a greater risk of being exposed to the virus at work. The results could also have been caused by having fewer daily obligations 
(e.g., less commuting time compared to on-site workers).

It should be noted that the data for this study were collected at the beginning of the pandemic (April 28 to June 28,2020$)$ during the first wave. Therefore, it is possible that some employees saw the situation as an opportunity to take it easy, an European study found that this was the case [74]. That said, $46.25 \%$ of the respondents mentioned that their workload had increased (see Table 1). On the other hand, in the longer term, it is probable that employees' perception of the current situation, and therefore their well-being, will change. Over time, stress is likely to increase as the pandemic and restrictive health measures continue. It will therefore be necessary to conduct additional studies to capture the long-term effects.

\subsection{Practical implications}

This study suggests that three potential stressors are associated with lower employee well-being. First, work-life imbalances can be corrected by encouraging supervisors to discuss and accommodate employees' work and life priorities through formal company policies and by creating a supportive company culture [89]. Second, workloads can be lowered by providing employees with appropriate breaks. Third, employee assistance programs could be made available to employees to help them deal with stressors (such as marital tension) during a pandemic. For instance, employers might offer visits with a psychologist.

Teleworking was also shown to have a direct and a moderating role on employee well-being in this study. To ensure that teleworking remains a positive factor on employee well-being both during the pandemic and afterward, employers should reach out to employees daily, if only to maintain social contact [8]. Companies can also educate their employees on the importance of creating a routine (shutting down the computer, stepping away from the desk from time to time), staying organized (keeping to-do lists, setting alarms to keep track of time), avoiding extreme multitasking (minimizing and prioritizing meetings, checking email at certain times during the day instead of continuously), and self-care (eating right, getting enough sleep, exercising), as suggested by LopezLeon et al., to stay healthy while teleworking [90]. Prior to the pandemic, Greer and Payne suggested maintaining continual communication with coworkers and supervisors on expectations, work progress, and availability; offering employees the flexibility to organize their work schedule and priorities; and providing employees with adequate technology and equipment [65].

\subsection{Limitations and suggestions for future research}

This study had some limitations. First, it was difficult to identify causal relationships between the cross-sectional data and the study variables. Some inverse relationships are possible because employees with a high level of well-being may underestimate their stressors. Second, our "snowball" sampling method generated a sample that was not representative of the general population of employees. However, as mentioned above, [82] found that this sampling strategy was valid and led to results indistinguishable from those using a standard sample. Also, even though recruiting subjects via social media may bias findings and limit generalizability, it allowed us to survey many employees and was the only way we could do so quickly during lockdown. Using this method, we were able to collect data early on in the first lockdown, between April 28 and June 28, 2020. Third, we were only able to test a limited number of variables due to the short length of our questionnaire, and the relationships we examined could also have been impacted by unobserved variables. We did not want to overload respondents during this difficult time, so we looked at only a few variables. It would have been interesting to include personality traits, since such they largely dictate how an individual views a stressor and thus how the individual responds to it. It would also have been interesting to look at the effects of workplace factors, such as human resources practices, leadership style, social support from colleagues and supervisors, recognition at work, and latitude in decision-making. Fourth, the fact that the measurements came from the same source means there may have been a common method bias. Finally, there may have been a selection bias since employees with more education were more likely to participate in the study because they were more likely to be familiar with online surveys.

Overall, although this study provides some answers to the determinants of well-being and the moderating role of teleworking during the first months of the COVID-19 pandemic, further studies are needed to understand how teleworking can change the role of stressors on well-being. In the future, the spectrum of stressors and resources should 
be broadened to better reflect their complexity. As so, it is necessary to evaluate resources at all levels suggested in the IGLO model [78]. This study focused on organizational and individual levels, but future studies should also considered leader and group levels. Subsequent studies may attempt to identify whether specific industries within the public sector are more likely to benefit from teleworking. Workplace factors, such as human resources practices, and individual factors, such as resiliency, emotional intelligence, self-efficacy, and coping strategies, should be integrated into future studies. Also, a representative sample of companies should be studied in future research to capture their effects.

Future studies should be carried out using longitudinal data to confirm and extend our research. This is especially true considering that, as the pandemic continues, it may increase the risk of serious, disabling mental health conditions [9]. Even when the pandemic is over, its effects on mental health and well-being will remain for a long time [9]. Therefore, the effects post-pandemic must also be verified.

\section{Conclusion}

We found that potential stressors directly influence employee well-being. We also found that teleworking seems to moderate the effects of potential stressors on well-being. More precisely, this study found that teleworking seems to be a moderator that relieves the negative effects of potential stressors on well-being. As so, it acted as a resource that moderated the effect that business sector had on employees' well-being during the first wave of the COVID-19 pandemic in Quebec, Canada. Thus, and to do the parallel with COR theory and IGLO model, it is an important organizational resource/human resources practice. This finding confirms the results of some previous studies carried out before and during COVID-19 pandemic (i.e. teleworking generally represents more advantages than disadvantages). Moreover, it provides an additional insight by specifying that teleworking may also play another important role, which is that of attenuating (i.e. moderating role) the effect of stressors. Canadians' private and public organizations should therefore strive to address work-life imbalances, workloads, and most importantly teleworking to ensure employee well-being. Especially, since well-being is an important foundation for employee motivation, effort, work behaviors, interpersonal relationships, commitment, and performance as previously stated. This represents a "win-win" situation for both employees and organizations. That said, it is important to keep in mind that this study was carried out during the first wave of the COVID-19 crisis in the province of Quebec, Canada. Therefore, it is not possible to generalize the results to other contexts or countries and to all employees.

\section{Conflict of interest}

The authors declare that they have no competing interests.

\section{References}

[1] Holmes EA, O'Connor RC, Perry VH, Tracey I, Wessely S, Arseneault L, et al. Multidisciplinary research priorities for the COVID-19 pandemic: a call for action for mental health science. The Lancet Psychiatry. 2020;7(6):547-60.

[2] Wang C, Pan R, Wan X, Tan Y, Xu L, McIntyre RS, et al. A longitudinal study on the mental health of general population during the COVID-19 epidemic in China. Brain, Behavior, and Immunity. 2020;87:40-7.

[3] Ho CS, Chee CY, Ho RC. Mental health strategies to combat the psychological impact of COVID-19 beyond paranoia and panic. Ann Acad Med Singapore. 2020;49(1):1-3.

[4] Bailey DE, Kurland NB. A review of telework research: Findings, new directions, and lessons for the study of modern work. Journal of Organizational Behavior: The International Journal of Industrial, Occupational and Organizational Psychology and Behavior. 2002;23(4):383-400.

[5] Kurland NB, Bailey DE. Telework: The advantages and challenges of working here, there, anywhere, and anytime. IEEE Engineering Management Review. 2000;28(2):49-60.

[6] Robertson MM, Maynard WS, Huang Y-hE, McDevitt JR, editors. Telecommuting: An Overview of Emerging Macroergonomics Issues. Proceedings of the Human Factors and Ergonomics Society Annual Meeting; 2002: SAGE Publications Sage CA: Los Angeles, CA.

[7] Tremblay D-G, Paquet R, Najem E. Telework: A Way to Balance Work and Family or an Increase in Work-Family Conflict? Canadian Journal of communication. 2006;31(3): 715-31.

[8] Galea S, Merchant RM, Lurie N. The mental health consequences of COVID-19 and physical distancing: The need for prevention and early intervention. JAMA Internal Medicine. 2020;180(6):817-8.

[9] Fiorillo A, Gorwood P. The consequences of the COVID19 pandemic on mental health and implications for clinical practice. European Psychiatry. 2020;63(1):e32.

[10] Erdogan B, Bauer TN, Truxillo DM, Mansfield LR. Whistle while you work: A review of the life satisfaction literature. Journal of Management. 2012;38(4):1038-83.

[11] Mount M, Ilies R, Johnson E. Relationship of personality traits and counterproductive work behaviors: The mediating effects of job satisfaction. Personnel Psychology. 2006;59(3):591-622. 
[12] Sonnentag S. Wellbeing and burnout in the workplace: Organizational causes and consequences. International Encyclopedia of the Social \& Behavioral Sciences. 2015; 25(2):537-40.

[13] Giorgi G, Shoss M, Di Fabio A. From organizational welfare to business success: higher performance in healthy organizational environments. Frontiers in Psychology. 2017;8:720.

[14] Spurk D, Straub C. Flexible employment relationships and careers in times of the COVID-19 pandemic. 2020; 119:103435

[15] Ryan RM, Deci EL. On happiness and human potentials: A review of research on hedonic and eudaimonic well-being. Annual Review of Psychology. 2001;52(1):141-66.

[16] Schütte S, Chastang J-F, Malard L, Parent-Thirion A, Vermeylen G, Niedhammer I. Psychosocial working conditions and psychological well-being among employees in 34 European countries. International Archives of Occupational and Environmental Health. 2014;87(8):897-907.

[17] Mäkikangas A, Kinnunen U, Feldt T, Schaufeli W. The longitudinal development of employee well-being: A systematic review. Work \& Stress. 2016;30(1):46-70.

[18] Meyers MC, van Woerkom M. Effects of a strengths intervention on general and work-related well-being: The mediating role of positive affect. Journal of Happiness Studies. 2017;18(3):671-89.

[19] Richter A, Näswall K. Job insecurity and trust: Uncovering a mechanism linking job insecurity to well-being. Work \& Stress. 2019;33(1):22-40.

[20] VanderWeele TJ, Trudel-Fitzgerald C, Allin P, Farrelly C, Fletcher G, Frederick DE, et al. Current recommendations on the selection of measures for well-being. Preventive Medicine. 2020;133:106004.

[21] Judge TA, Thoresen CJ, Bono JE, Patton GK. The job satisfaction-job performance relationship: A qualitative and quantitative review. Psychological Bulletin. 2001;127(3): 376.

[22] Wood S, Van Veldhoven M, Croon M, de Menezes LM. Enriched job design, high involvement management and organizational performance: The mediating roles of job satisfaction and well-being. Human Relations. 2012;65(4): 419-45.

[23] Węziak-Białowolska D, Białowolski P, McNeely E. Worker's well-being. Evidence from the apparel industry in Mexico. Intelligent Buildings International. 2019;11(3-4): 158-77.

[24] Topp CW, Østergaard SD, Søndergaard S, Bech P. The WHO-5 Well-Being Index: a systematic review of the literature. Psychotherapy and Psychosomatics. 2015;84(3): 167-76.

[25] Lyubomirsky S, King L, Diener E. The benefits of frequent positive affect: Does happiness lead to success? Psychological Bulletin. 2005;131(6):803.

[26] Bech P, Olsen LR, Kjoller M, Rasmussen NK. Measuring well-being rather than the absence of distress symptoms: a comparison of the SF-36 Mental Health subscale and the WHO-Five well-being scale. International Journal of Methods in Psychiatric Research. 2003;12(2):85-91.

[27] Gao J, Weaver SR, Dai J, Jia Y, Liu X, Jin K, et al. Workplace social capital and mental health among Chinese employees: a multi-level, cross-sectional study. PloS One. 2014;9(1):e85005.

[28] Nielsen K, Randall R. The importance of employee participation and perceptions of changes in procedures in a teamworking intervention. Work \& Stress. 2012;26(2): 91-111.
[29] Hobfoll SE. Conservation of resources: A new attempt at conceptualizing stress. American Psychologist. 1989; 44(3):513

[30] Gröpel P, Kuhl J. Work-life balance and subjective wellbeing: The mediating role of need fulfilment. British Journal of Psychology. 2009;100(2):365-75.

[31] Fotiadis A, Abdulrahman K, Spyridou A. The mediating roles of psychological autonomy, competence and relatedness on work-life balance and well-being. Frontiers in Psychology. 2019;10:1267.

[32] Lunau T, Bambra C, Eikemo TA, van Der Wel KA, Dragano N. A balancing act? Work-life balance, health and wellbeing in European welfare states. The European Journal of Public Health. 2014;24(3):422-7.

[33] Baldwin JN, Farley QA. Comparing the Public and Private Sectors in the United States: A review of the empirical research. In: Farazmand A, editor. Handbook of comparative and developmental public administration. New York: Marcel Dekker; 2001. p. 119.

[34] Steel BS, Warner RL. Job satisfaction among early labor force participants: Unexpected outcomes in public and private sector comparisons. Review of Public Personnel Administration. 1990;10(3):4-22.

[35] Wright BE, Davis BS. Job satisfaction in the public sector: The role of the work environment. The American Review of Public Administration. 2003;33(1):70-90.

[36] Imamoğlu EO, Beydoğan B. Impact of Self-Orientations and Work-Context-Related Variables on the Well-Being of Public-and Private-Sector Turkish Employees. The Journal of Psychology. 2011;145(4):267-96.

[37] Shaw JB, Weekley JA. The effects of objective work-load variations of psychological strain and post-work-load performance. Journal of Management. 1985;11(1):87-98.

[38] Karasek RA. Job demands, job decision latitude, and mental strain: Implications for job redesign. Administrative Science Quarterly. 1979:285-308.

[39] Ariza-Montes A, Arjona-Fuentes JM, Han H, Law R. Work environment and well-being of different occupational groups in hospitality: Job Demand-Control-Support model. International Journal of Hospitality Management. 2018;73:1-11.

[40] Ilies R, Dimotakis N, De Pater IE. Psychological and physiological reactions to high workloads: implications for well-being. Personnel Psychology. 2010;63(2):407-36.

[41] Pace F, D'Urso G, Zappulla C, Pace U. The relation between workload and personal well-being among university professors. Current Psychology. 2019:1-8.

[42] Parent-Lamarche A, Marchand A. Well-being at work from a multilevel perspective: what is the role of personality traits? International Journal of Workplace Health Management. 2019;12(5):298-317.

[43] Marchand A, Demers A, Durand P. Does work really cause distress? The contribution of occupational structure and work organization to the experience of psychological distress. Social Science \& Medicine. 2005;61(1):1-14.

[44] Parent-Lamarche A, Marchand A. A study on the moderator effect of personal traits on the relation between work Organization's conditions and psychological distress. Psychologie de travail et des Organisations. 2010;16(1):79-99.

[45] Xie Z, Wang A, Chen B. Nurse burnout and its association with occupational stress in a cross-sectional study in Shanghai. Journal of Advanced Nursing. 2011;67(7):1537-46.

[46] Becker C, Kirchmaier I, Trautmann ST. Marriage, parenthood and social network: Subjective well-being and mental health in old age. PloS One. 2019;14(7):e0218704. 
[47] Margelisch K, Schneewind KA, Violette J, Perrig-Chiello P. Marital stability, satisfaction and well-being in old age: variability and continuity in long-term continuously married older persons. Aging \& Mental Health. 2017;21(4):389-98.

[48] Qian Y, Knoester C. Parental status and subjective wellbeing among currently married individuals in China. Journal of Family Issues. 2015;36(10):1351-76.

[49] Klersy C, Callegari A, Martinelli V, Vizzardi V, Navino C, Malberti F, et al. Burnout in health care providers of dialysis service in Northern Italy-a multicentre study. Nephrology Dialysis Transplantation. 2007;22(8):2283-90.

[50] Headey B, Wooden M. The effects of wealth and income on subjective well-being and ill-being. Economic Record. 2004;80: S24-S33.

[51] Stevenson B, Wolfers J. Subjective well-being and income: Is there any evidence of satiation? American Economic Review. 2013;103(3):598-604.

[52] Dai JM, Collins S, Yu HZ, Fu H. Combining job stress models in predicting burnout by hierarchical multiple regressions: a cross-sectional investigation in Shanghai. Journal of Occupational and Environmental Medicine. 2008;50(7): 785-90.

[53] Garrosa E, Rainho C, Moreno-Jimenez B, Monteiro MJ. The relationship between job stressors, hardy personality, coping resources and burnout in a sample of nurses: A correlational study at two time points. International Journal of Nursing Studies. 2010;47(2):205-15.

[54] Milliken FJ, Kneeland MK, Flynn E. Implications of the COVID-19 pandemic for gender equity issues at work. Journal of Management Studies. 2020;57(8):1767-72.

[55] Xiong J, Lipsitz O, Nasri F, Lui LM, Gill H, Phan L, et al. Impact of COVID-19 pandemic on mental health in the general population: A systematic review. Journal of Affective Disorders. 2020;277:55-64.

[56] Horesh D, Kapel Lev-Ari R, Hasson-Ohayon I. Risk factors for psychological distress during the COVID-19 pandemic in Israel: Loneliness, age, gender, and health status play an important role. British Journal of Health Psychology. 2020;25(4):925-33.

[57] Özdin S, Bayrak Özdin Ş. Levels and predictors of anxiety, depression and health anxiety during COVID-19 pandemic in Turkish society: The importance of gender. International Journal of Social Psychiatry. 2020:0020764020927051.

[58] Jiang L, Lavaysse LM. Cognitive and affective job insecurity: A meta-analysis and a primary study. Journal of Management. 2018;44(6):2307-42.

[59] Sverke M, Hellgren J, Näswall K. No security: a meta-analysis and review of job insecurity and its consequences. Journal of Occupational Health Psychology. 2002; 7(3):242.

[60] De Witte H, Pienaar J, De Cuyper N. Review of 30 years of longitudinal studies on the association between job insecurity and health and well-being: Is there causal evidence? Australian Psychologist. 2016;51(1):18-31.

[61] Guynn J. Yahoo CEO Marissa Mayer causes uproar with telecommuting ban. Los Angeles Times. 2013;26.

[62] Goudreau J. Back to the stone age? New Yahoo CEO Marissa Mayer bans working from home. Forbes Retrieved from https://www.forbes.com/sites/jennagoudreau/2013/ 02/25/back-to-the-stoneage-new-yahoo-ceo-marissamayer-bans-working-fromhome/?sh $=33 \mathrm{c} 16 \mathrm{cdc} 3295$

[63] Baert S, Lippens L, Moens E, Weytjens J, Sterkens P. The COVID-19 crisis and telework: A research survey on experiences, expectations and hopes. 2020. Retrived from https://ssrn.com/abstract=3596696
[64] Hamouche S. COVID-19 and employees' mental health: stressors, moderators and agenda for organizational actions. Emerald Open Research. 2020;2(15):15.

[65] Greer TW, Payne SC. Overcoming telework challenges: Outcomes of successful telework strategies. The Psychologist-Manager Journal. 2014;17(2):87.

[66] Henke RM, Benevent R, Schulte P, Rinehart C, Crighton KA, Corcoran M. The effects of telecommuting intensity on employee health. American Journal of Health Promotion. 2016;30(8):604-12.

[67] Tavares AI. Telework and health effects review. International Journal of Healthcare. 2017;3(2):30.

[68] Sardeshmukh SR, Sharma D, Golden TD. Impact of telework on exhaustion and job engagement: A job demands and job resources model. New Technology, Work and Employment. 2012;27(3):193-207.

[69] Charalampous M, Grant CA, Tramontano C, Michailidis E. Systematically reviewing remote e-workers' well-being at work: A multidimensional approach. European Journal of Work and Organizational Psychology. 2019;28(1): 51-73.

[70] Bonacini L, Gallo G, Scicchitano S. Working from home and income inequality: risks of a 'new normal'with COVID-19. Journal of Population Economics. 2021;34(1):303-60.

[71] Belzunegui-Eraso A, Erro-Garcés A. Teleworking in the Context of the COVID-19 Crisis. Sustainability. 2020;12(9): 3662.

[72] Hobfoll SE, Halbesleben J, Neveu J-P, Westman M. Conservation of resources in the organizational context: The reality of resources and their consequences. Annual Review of Organizational Psychology and Organizational Behavior. 2018;5:103-28.

[73] Prasad K, Vaidya R, Mangipudi M. Effect of Occupational Stress and Remote Working on Psychological Wellbeing of Employees: An Empirical Study During COVID-19 Pandemic with Reference to Information Technology Industry around Hyderabad. Researchgate; 2020. Retrived from https://www.researchgate.net/profile/Kdv-Xxx/publicati on/341778937_Effect_of_occupational_stress_and_remote working_on_psychological_well-being_of_employees_an empirical_analysis_during_covid-19_pandemic_concern ing_information_technology_industry_in_hyderabad/links/ 5ed3c956299bf1c67d2cd465/Effect-of-occupationalstress-and-remote-working-on-psychological-well-beingof-employees-an-empirical-analysis-during-covid-19pandemic-concerning-information-technology-industryin-hyderabad.pdf

[74] Ipsen C, van Veldhoven M, Kirchner K, Hansen J. Six Key Advantages and Disadvantages of Working from Home in Europe during COVID-19. Int J Environ Res Public Health. 2021;18:1826. Retrived from https://doi.org/10.3390/ijerph 18041826

[75] Kirchner K, Ipsen C, Hansen JP. COVID-19 leadership challenges in knowledge work. Knowledge Management Research \& Practice. 2021:1-8. Retrived from https://www. tandfonline.com/doi/full/10.1080/14778238.2021.1877579 ?casa_token $=9 \mathrm{qG} 9 \mathrm{~N} 2 \mathrm{csxFwAAAAA} \% 3$ AniLBImOgTjIpc L0a3JJsqi5sMU1fr2xX-10Pb293JZXA8APMjkLH6BOBUSnMOusrz-yrpYsOGbp

[76] Eurofound. Publications Office of the European Union. Luxembourg; 2020. Retrived from https://www.eurofound. europa.eu/fr/publications

[77] Bolisani E, Scarso E, Ipsen C, Kirchner K, Hansen JP. Working from home during COVID-19 pandemic: lessons learned and issues. Management \& Marketing Challenges for the 
Knowledge Society. 2020;15(s1):458-76. Retrived from https://sciendo.com/article/10.2478/mmcks-2020-0027

[78] Nielsen K, Nielsen MB, Ogbonnaya C, Känsälä M, Saari E, Isaksson $\mathrm{K}$. Workplace resources to improve both employee well-being and performance: A systematic review and metaanalysis. Work \& Stress. 2017;31(2):101-20.

[79] Guest DE. Human resource management and employee well-being: Towards a new analytic framework. Human Resource Management Journal. 2017;27(1):22-38.

[80] Brooks SK, Webster RK, Smith LE, Woodland L, Wessely S, Greenberg N, et al. The psychological impact of quarantine and how to reduce it: rapid review of the evidence. The Lancet. 2020;395(10227):912-20.

[81] Xiang Y-T, Yang Y, Li W, Zhang L, Zhang Q, Cheung T, et al. Timely mental health care for the 2019 novel coronavirus outbreak is urgently needed. The Lancet Psychiatry. 2020;7(3):228-9.

[82] Casler K, Bickel L, Hackett E. Separate but equal? A comparison of participants and data gathered via Amazon's MTurk, social media, and face-to-face behavioral testing. Computers in Human Behavior. 2013;29(6):2156-60.

[83] Heun R, Bonsignore M, Barkow K, Jessen F. Validity of the five-item WHO Well-Being Index (WHO-5) in an elderly population. European Archives of Psychiatry and Clinical Neuroscience. 2001;251(2):27-31.

[84] Tabachnick BG, Fidell LS. Using multivariate statistics: International Edition. Boston: Pearson; 2013.

[85] Dawson JF. Moderation in management research: What, why, when, and how. Journal of Business and Psychology. 2014;29(1):1-19.

[86] Merchant RM, Lurie N. Social media and emergency preparedness in response to novel coronavirus. Jama. 2020; 323(20):2011-2.

[87] Mayo M, Gomez-Mejia L, Firfiray S, Berrone P, Villena VH. Leader beliefs and CSR for employees: the case of telework provision. Leadership \& Organization Development Journal. 2016;37(5):609-34.

[88] Sullivan TA. Greedy institutions, overwork, and work-life balance. Sociological Inquiry. 2014;84(1):1-15.

[89] Talukder AMH. Supervisor support and organizational commitment: The role of work-family conflict, job satisfaction, and work-life balance. Journal of Employment Counseling. 2019;56(3):98-116.

[90] Lopez-Leon S, Forero DA, Ruiz-Díaz P. Recommendations for working from home during the pandemic (and Beyond). Work. 2020(Preprint):1-5. 